\title{
Quasiconferência crepuscular sobre Quarteto de Heiner Müller
}

\author{
Anabela Mendes
}

Vivemos demoniacamente toda a nossa inocência. Herberto Helder (2013: 13)

Todos temos no sangue espírito republicano, tal como temos a sifilis nos ossos: estamos infectados de democracia e sifilis. Charles Baudelaire (apud Benjamin 1974: 515)

Gostaria de pôr contra mim a raça humana inteira. Vejo nisso uma volúpia que me consolaria de tudo o resto.

Charles Baudelaire (a sua mãe) (apud Benjamin 1974: 516)

\section{Nota intima}

Precisei de traduzir Quartett de Heiner Müller para me pacificar em relação a uma história de sedução na qual fui cúmplice durante dois anos. Na altura em que fiz a tradução, escrevia ainda numa Underwood dos anos quarenta que o meu pai usara com devoto empenho. Ao oferecer-me essa peça-relíquia, o meu pai queria apenas que nada me faltasse para ser uma profissional ágil. Nunca ele soube como a agilidade dos dedos nas teclas, muitas vezes batidas com a força e não com a perícia, contribuíram para a regenerabilidade dialéctica e progressiva sobrevivência a esse episódio singular na minha biografia.

Fiquei assim entre o texto de Heiner Müller, o texto que procurei devolver-Ihe como proposta em português, e a minha história pessoalissima enriquecida então pelo jogo de trocas e pelos muitos discursos que esse vai e vem inspirou.

Traduzi como terapia e foi a partir dessa opção que integrei posteriormente Quarteto nos meus objectos de estudo. A minha tradução foi cara a Rogério de Carvalho que dela fez encenação, em 2004, para um projecto de Júlia Correia, na Escola Superior de Música e Artes do Espectáculo no Porto.

0 dactiloscrito de 33 páginas, que nunca foi publicado, atraiu também, muitos anos depois, o Alexandre Calado e a Sandra Hung, dois actores, professores e encenadores, com quem já trabalhei dentro e fora de Portugal. A eles me liga terna e muito devota cumplicidade que esteve na origem desta nossa nova colaboração.

\section{0 que vem à superfície e parece inusitado}

Esta peça fala de ligações perigosas entre pessoas. Em que consiste esse perigo? 0 que é que ele anuncia? Porque é que Pierre-Ambroise-François Choderlos de Laclos terá escolhido este assunto que viria a motivar Heiner Müller dois séculos depois? De que é que Laclos queria defender os seus leitores contemporâneos, maioritariamente aristocratas e já futuros aspirantes ao aburguesamento, com esse seu romance epistolar concebido como teialabirinto? A quem aproveitou a distinção entre aristocratas e burgueses na época de Laclos, que tanto ocupou Müller, ao ponto de se ter tornado mínima a destrinça entre uns e outros, sobretudo quando abrir falência passou a ser um mero estratagema negocial que se entretém a descontrolar o mundo?

0 que deixa o ser humano de dominar quando o instinto se sobrepõe à lógica do pensamento? Ou melhor: o que escapa à lógica do pensamento quando a radicalização do jogo é conduzida por linguagem que argumenta, mas que também implode o silêncio, abrindo a porta à alienação e ao gesto hostil refinado pela acção?

Neste processo encontram-se potencialmente todos os seres humanos - homens e mulheres - que uma vez feridos de morte, em cada vida particular, pela estocada quase final (e esta pode ser metaforicamente apenas a gota que se derrama de um copo que deixa de ser capaz de a conter), imprimem novo alento às forças que ainda Ihes restam, momentaneamente desconhecedores de que podem não ser capazes de sobre elas exercer controlo, fazendo sucumbir quem se thes opõe. Sermos potenciais assassinos e assassinos de facto é algo de que não nos livramos nunca, mesmo quando acreditamos que temos capacidade de superar em nós o natural demoníaco que nos molda.

Serão assassinos, não apenas como estratégia representacional, todos os actores que criarem oposição a outros actores e dela resultaram morte em cena. Poderão não vir a ser assassinos aqueles que vestirem a pele de assassinos e aqueles que os virem fazer de assassinos? Quem poderá alguma vez dizer - desta água não beberei? Quem poderá alguma vez acrescentar - jamais usarei esta faca para matar alguém? Quem se poderá livrar de afirmar
Anabela Mendes é professora da Faculdade de Letras da Universidade de Lisboa e investigadora do Centro de Estudos de Comunicação e Cultura da Universidade Católica Portuguesa. Mantém actividade regular na área da tradução e escrita para teatro, dramaturgia e encenação. 


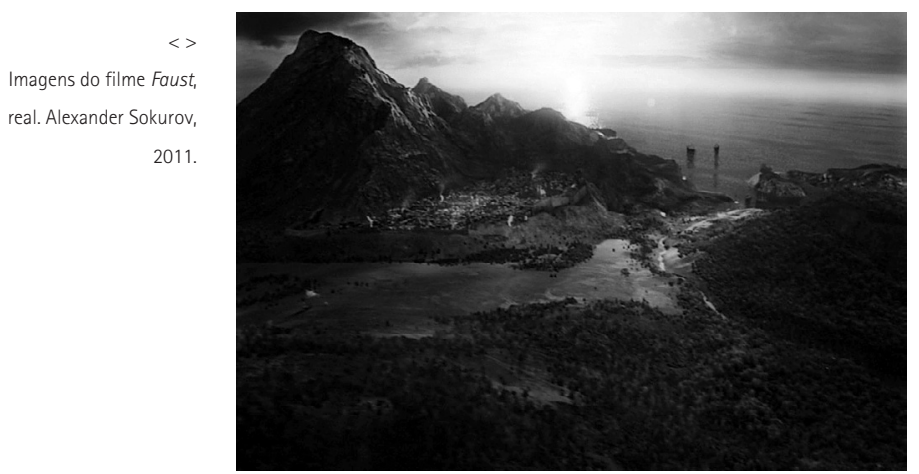

- eu pus as minhas mãos à volta do teu pescoço para te estrangular?

Quarteto de Heiner Müller prepara para cena sucessivos combates que oferece ao par protagonista, urdindo para ele palavras-bomba e palavras-pomba dificeis de dizer por dentro. Muitas vezes elas fazem-nos crer que a tensão entre contrários se serve metaforicamente da esgrima ou da arte de atirar bestas como máscara que transforma a desolação em marcha triunfante. Num frente a frente homem e mulher, e seus desdobramentos, retiramse do apuro ficcional para voltarem a ser predador e presa, sabendo que um e outro serão vencidos pelo jogo da enredada arte que, aliás, os conduzirá ao perecimento sem retorno com que a peça se conclui.

À medida que o discurso vai perdendo o viço na casa do argumento, o par de actores e a sua mascarada dificilmente resistirão a visitar nos alçapões de cada um os fantasmas residentes. 0 confronto nunca deixa de ser um processo em que o poder da rivalização os obriga a arrancar um ao outro segredos a que eles próprios não podem senão submeter-se. Fonte de inspiração mas também uma ameaça, o jogo e o anti-jogo sublinham de forma inevitável em Quarteto a presença da terrorização comportamental, contra a qual já Baudelaire cinicamente se insurgia.

Escrito como contra-cena ácida, meliflua aqui e acolá, e até com pinceladas bíblicas que atestam o vaticínio quase inquestionável, ou destapam em versos schillerianos o louvor harmonioso do lar burguês, Quarteto cria, a um tempo, uma espessura vocal e de movimento que faz sobressair a falibilidade da anatomia humana; a outro tempo, porém, confronta-nos com a sobreposição de uma visão ecléctica a uma visão apaixonada. Merteuil e Valmont já não se encontram disponíveis para serem afectados pelo ardor da carne, o que não os impede de quererem continuar a ver tudo, e de terem a consciência de que nada Ihes escapará, ao transformarem as ruinas das suas

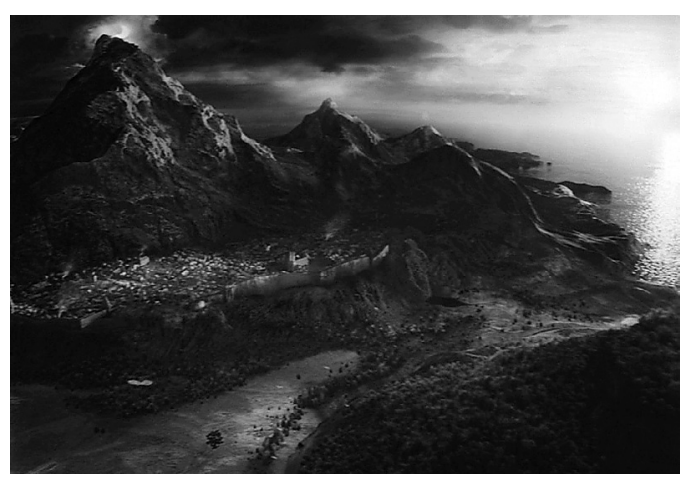

pessoas em teses agarradas umas às outras pelo fio cíclico do tempo que os contempla.

Nesta comédia cínica a análise executa-se decompondo qualitativamente a essência humana a partir de um ponto de vista europeu, que sabe ser o ocidente confundivel hoje com um oriente de muitos matizes e colorações. 0 cenário civilizacional desta peça é balizado pelo eixo "Espaço/Tempo: Salão aristocrata antes da Revolução Francesa/Bunker depois da terceira guerra mundial". Conflito, adição, violência e destruição parecem associarse num antes da democracia representativa e num depois dela, exactamente quando a sua legitimidade já nem sequer é necessária. 0 laboratório anatómico confirma em cada órgão, desde a pele ao coração, o programa cognitivo e afectivo que está para além das classes sócioeconómicas e políticas. Perguntamo-nos - foi Müller um autor pessimista antes e depois de um quadro pósmoderno? Respondemos - Müller foi um iluminado Prometeu dialéctico, desalinhado, crítico e mordaz.

\section{Estará previsto um Burger King no tal bunker extemporâneo?}

Escreve Müller Quarteto como ajuste de contas pessoal e íntimo, mas escreve-o também para estruturar pensamento em torno da ideia e prática revolucionárias e suas convulsões. Num tempo em que as revoluções entraram na História com patines palacianas, porque a burguesia deixou de conseguir livrar-se do bicho que a corrói e do cheiro a mofo que a impregna, esta peça ocupa-se, num registo muito peculiar, de como se torna possivel esvaziar politica e socialmente uma classe - a burguesia - enquanto categoria dinâmica cuja função e horizonte começaram por ter em vista o bem-estar, o progresso e a realização do ser humano nas suas múltiplas perspectivas e anseios. Como guardadora e agente de valores e princípios democráticos, a burguesia foi perdendo de vista a nobre tradição renascentista, enquanto se 


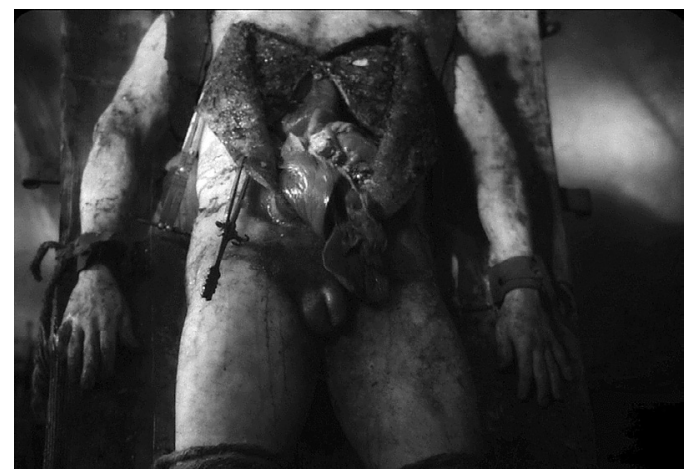

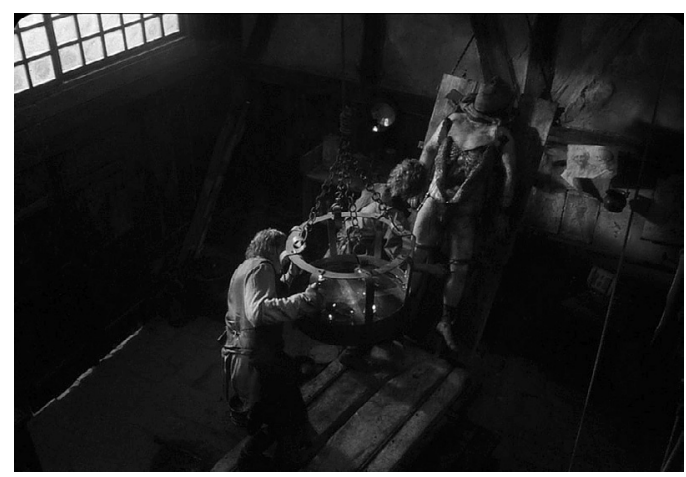

entretinha a desfiar a tessitura do legado greco-latino, exibindo uma a uma as ruínas de templos e ágoras onde a palavra foi lei e prece dos homens.

Chegou um tempo, e este é de tal maneira lato que nos perdemos na sua quantificação, em que uma certa ou incerta burguesia, saída das revoluções que precederam o nosso século, se perfilou sem pudor a coberto de negócios e deu largas àquele espírito empreendedor que nem sempre se mostrou transparente. E assim ela sucumbiu à facilidade com que o luxo se torna num amante obsceno, concedeu ao desperdício estatuto de impropério, acumulou no excesso consumista um tempo sem lugar, travou-se de desejo pela corrupção, violou-se e deixou-se violar pelo vício, foi pasto da concupiscência, escancarou-se à sedução mercantil de um capitalismo de ganância com regras concebidas para serem ferozmente ignoradas ou poderem apenas valer como mera trivialidade pública. Vivemos hoje colectivamente o rescaldo amargo desta incontrolada desordem, que Müller tão bem escalpelizou nas suas peças, e em que a noção de classe deixou de fazer sentido, porque a agonia dos protagonistas não passa de um arremedo prostituível em privado ou à vista de todos.

É preciso que nada sobeje entre o espaço de um salão aberto a aristocratas (alguém saberá ainda o que isso é?), afeiçoados ao decrépito e ao decadente de monarquias absolutistas (o nepotismo ainda não acabou), e o espaço de um bunker firme, preparado em cimento sob fórmula de resistência prolongada, que possa albergar um ou outro sobrevivente de uma cada vez mais acautelada Terceira Guerra Mundial. Entre salão e bunker paira o espaçotempo de uma burguesia que perdeu a medula espinal e a capacidade de criar nexo através de buracos intervertebrais. Grande parte da espécie humana vive hoje indignada, clama por justiça (será que não escutou em excesso o canto da sereia?), enreda-se sem resposta plausivel numa pobreza sobrevivente de constante precariedade.

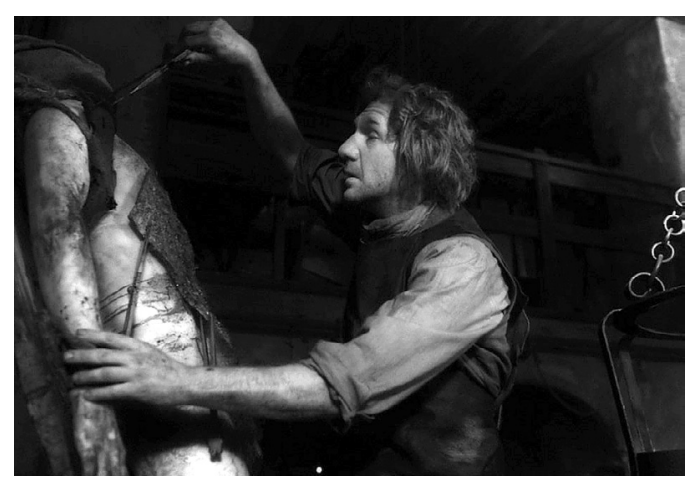

Isto é também a peça de Müller, aquela que dá protagonismo à carne fraca e às mucosas sedentas que anseiam pela morte. Morte-punição. Morte-libertação.

\section{Da repetição e da máscara da não-repetição}

A morte é sedutora e possui muitas máscaras. Triturar a carne e os seus dejectos, dar a isso forma apetecível com sabor colorido, continua a encher com cupidez e gula a barriga da populaça. Já o jejum forçado, que mingua as visceras e reduz a massa corpórea, com especial incidência na genitália interna e externa, no coração, de cada vez que é interrompido ou superado, produz repulsa e êxtase em simultâneo.

Depois de terem experimentado a máscara em perfeitas variações, Merteuil e Valmont entregam-se ao exercício de expurgação do mal, assassinam metodicamente em cada um o que em si lhes escapa e não foram capazes de controlar ou transformar. Não se trata aqui da devastação em série causada por um qualquer sequioso donjuanismo, sob forma masculina ou feminina, mas de um macabro e muito distinto exercício meticuloso e ritualístico de vingança violenta sem finalidade, a não ser dar espaço no tempo ao estrito campo do mortífero prazer.

A peça de Heiner Müller é também difícil por todo este enredamento. As motivações que desencadeiam o hediondo acto vingador (Merteuil mata Valmont e morre da sua própria podridão) que diante de nós tem lugar, justificam a dialéctica de que matar alguém é, de facto, um acto bárbaro mas lúbrico e orgásmico. Nele se consuma a essência da mostração do discurso e os seus excessos. Aquilo que provavelmente mais nos surpreende é que não estamos perante um fraco e um forte e, portanto, perante um modelo banal que agencia violência e poder. À nossa frente representa uma dupla de aristocratas, ora fortes na sua fraqueza ora fracos na sua fortaleza, chamemosIhe assim, que tenta dar cobertura ao que de mais nobre existiu nos códigos de honra da cavalaria medieval europeia
Imagens do filme Faust, real. Alexander Sokurov, 2011. 

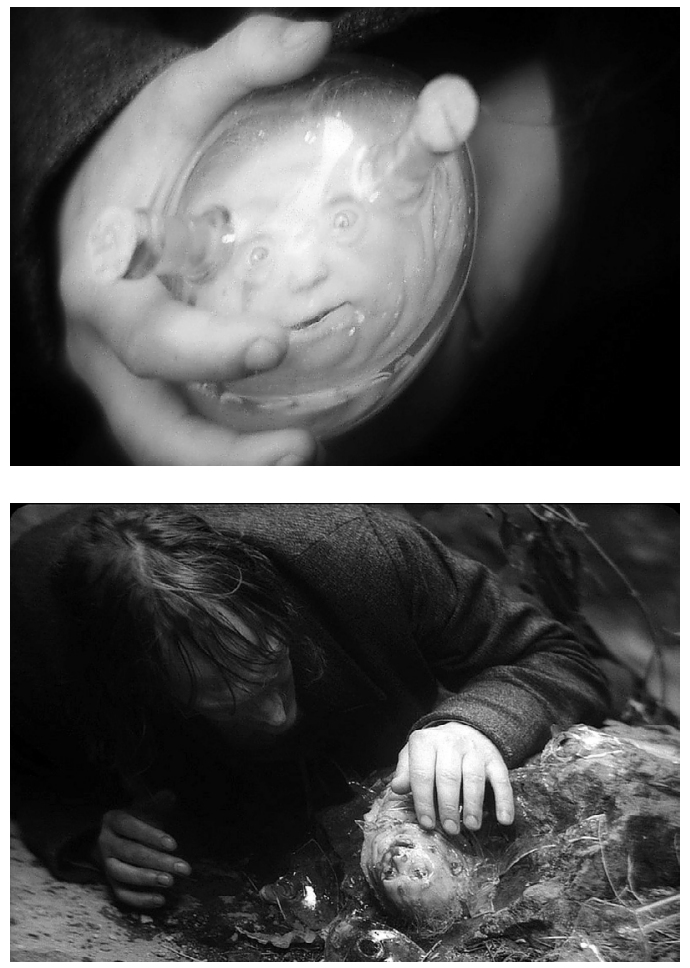

- a nobreza do gesto em justas e torneios. Mas essa é também uma máscara que acaba por cair por terra, quando o polimento com que um trata o outro e vice-versa se esboroa e transforma em crueza lapidar, só satisfeita pelo mútuo esfacelamento dialogante e coroado com muito sangue e todas as visceras. Nada restará intacto depois do combate entre pares: se não te posso vencer pela persuasão, venço-te aniquilando-te. Se não te consigo converter à minha ideologia, à ideologia do meu corpo, desfaço-me de ti, envenenando-te. Auto-destruição e destruição do Outro pontuam a infinita partitura desta peça tão original e tão velha como a humanidade, salvo os panejamentos epocais.

A perda do lugar de si, que nenhum tempo colectivo ou nenhuma condição social e política conseguem preencher de forma satisfatória, afere-se em Quarteto quando o privado se torna público ou quando privado e público são indistinguiveis e deixam de estar sujeitos a nomeação.

Que dizer àqueles que acreditam poder a radicalização de comportamentos responder favoravelmente aos anseios da fé ou da militância política? Como encarar o bom ou o mau andamento de todo o tipo de negócios do mundo, quando o mundo deixou de ser capaz de disso se dar conta? E caso ele se dê conta desse desgoverno, como poderemos contar com o mundo para nos libertar de sermos escravos da concupiscência criminosa que repentinamente nos possa atingir? Será que sob a égide do mais puro anonimato ascendemos a protagonistas, sem que os nossos nomes jamais interessem a alguém? Em boa verdade ninguém se ocupa daqueles que não são conhecidos como responsáveis até ao momento em que os seus actos a isso obriguem. Será que em algum momento dos seus comportamentos, gestos e linguagem intimos, Merteuil e Valmont tomam verdadeira consciência de que matar também é um acto licencioso do qual pode emergir um prazer libertino? 0 que será que eles sentem?
Sobrepondo ao domínio ficcional a realidade que o engendra, poderá a coberto do anonimato cada terrorista aperceber-se de que dentro de si habita um libertino, um escravo liberto, como nos ensinou a língua latina?

Aos olhos dos libertinos, o desregramento, a animalidade dos actos próprios não se fundamentam em julgamento moral. Desse ponto de vista o libertino partilha com o terrorista a similitude da dinâmica do instinto. Ambos são seres teleológicos e vão sempre até ao fim das suas estradas. Em nome de um prazer preparado com requinte e despido de emoção, libertino e terrorista podem até trocar de máscara entre si, desferirão golpe atrás de golpe, usarão a bomba como traje, com elástica frieza, farão da crueldade uma motivação constante. Matar nestas circunstâncias pressupõe que não haja nem dó nem piedade. Estes seres ficariam paralisados se Ihes caisse em cima um pingo de comoção. 0 que thes sobreviverá? 0 que nos sobreviverá? Como sobreviveremos?

Aquilo que consideramos como violência gratuita, mas que outros assim não entendem, resulta de uma relação de causa e efeito predatórios, apresenta-se como comportamento sexualmente aditivo a que nem a exaustão dos corpos consegue pôr fim, mora ao nosso lado todos os dias e toma connosco café.

\section{A autópsia como acto de conhecimento}

Em nome do entendimento comum e da percepção directa da passagem do tempo sobre as suas naturezas anatómica e fisiológica, Merteuil e Valmont enfrentam-se num combate derradeiro em que o extremar de posições e disposições inclui um momento coprofilico, forma degenerescente de excitação sexual. Tem esta fantasia a função de antecipar no prazer sexual animalesco (o cheiro das fezes e da urina é sempre uma pista) o incontrolável dominio do irracional, o não-retorno da temporalidade, a proximidade da morte. Tendo ambos "trabalhado" sobre o conhecimento e o prazer do corpo em vida, resta-Ihes 

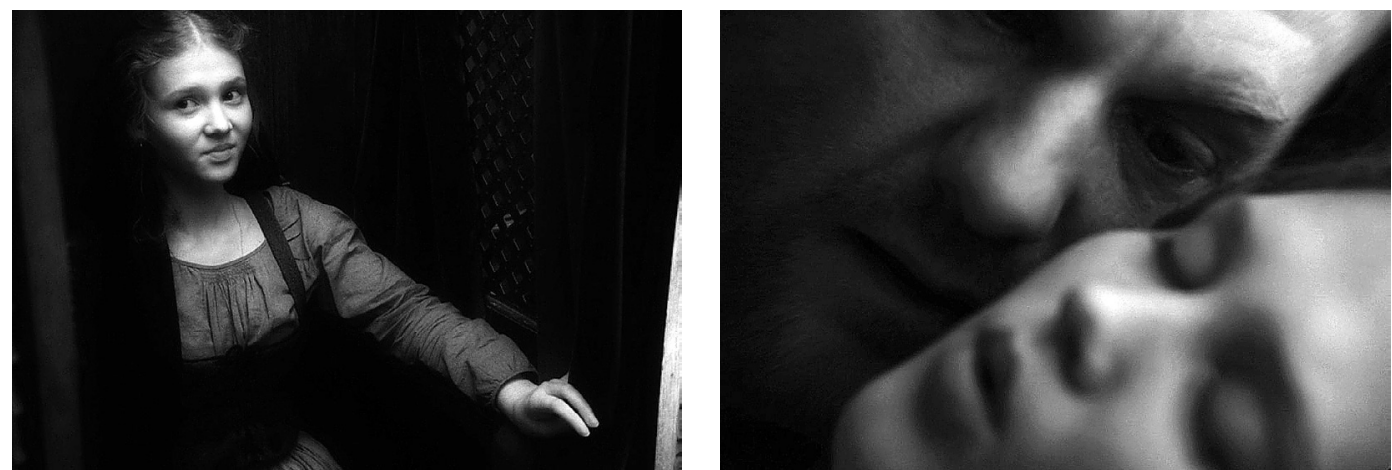

$<>$

Imagens do filme Faust, real. Alexander Sokurov, 2011.
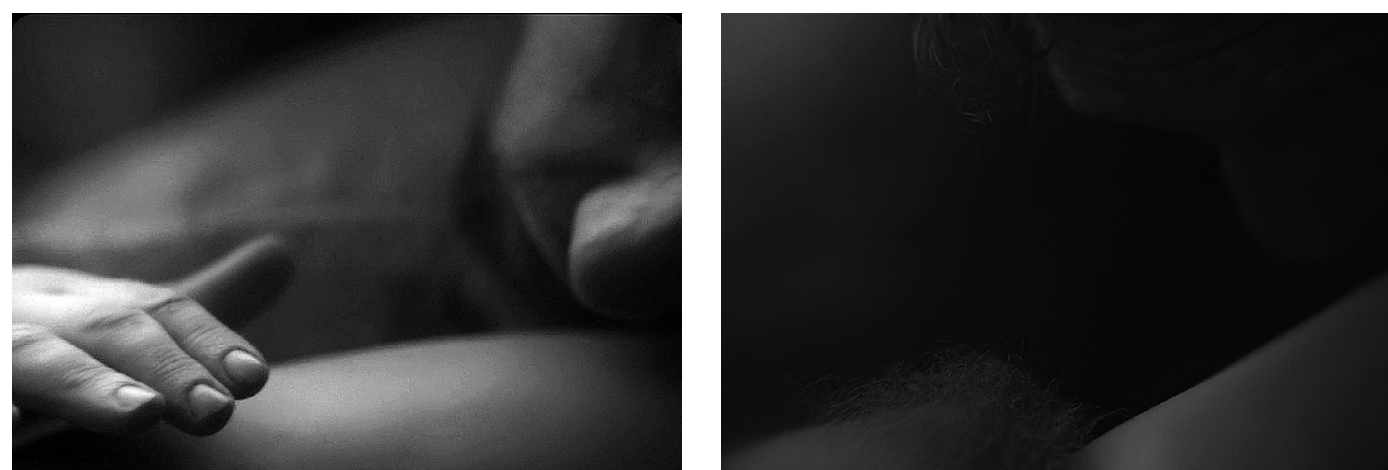

$<>$

Imagens do filme Faust real. Alexander Sokurov, 2011

abandonarem-se a uma morte previamente combinada e sequencial antes que a carne se putrefaça. Primeiro o veneno, como parodização do fim trágico, depois o cancro como corruptor invasivo, selos definitivos da vitória do mal a que a arte venatória antecipou possessão e fusão.

Não nos surpreende, pois, que Quarteto possa conter ainda na sua essência a germinação e o desenvolvimento de uma metodologia de dissecação que faz do discurso e do acto de representar o campo para uma autópsia artística como exercicio de terror. Será através desta que o ritual entre o corpo e o corpo nos revela o não-lugar da alma, a instância última que anima como sopro vital a nossa existência.

Valmont/Merteuil esgotam-se um ao outro por incapacidade de se relacionarem como antes fôra - a consciência da perda de inocência parece fatal -, presos ao horror com que encaram o envelhecimento que já grita na flacidez da pele, na secura das mucosas, no murchar da virilidade, entre tantos outros sinais que avivam dentro e fora de cada um deles um fim próximo. Eles inquietamse com a fugacidade imperfeita do prazer serial, confirmam pelos golpes do discurso a corrosão impiedosa que desfaz carne e espírito, cheiram mal e não se conformam com o cair das máscaras. Só a condição de cadáver Ihes pode responder como libertação pela dor que um ao outro infligiram, pelo medo de serem eles próprios e que ainda os devora, ao entregarem-se sob a forma de sacrificio a uma última celebração conjunta.

Conhecendo finalmente a inevitabilidade da morte e as suas consequências, o par libertino acede ao não-ser. Assassinio por envenenamento e doença cancerosa (em Laclos era a escarlatina) coroam como instâncias punitivas o excesso, o desregramento, a violência e a bestialidade de que a natureza humana não se consegue desenvencilhar mesmo que paradoxalmente continue a acreditar nessa hipótese.

Em cada pé uma alma andarilha

A procura da alma como forma de equilibrio maior entre o infinitamente grande e o infinitamente pequeno, o permanente exercício entre o conhecimento empírico e o conhecimento especulativo, a enorme perplexidade perante aquilo que nos escapa, que nenhuma interpretação parece resolver, e aquilo que efectivamente somos e que nem sempre nos dispomos a aceitar, são questões comuns a Quarteto de Heiner Müller e ao recente filme de Alexander Sokurov, Faust (Leão de Ouro no 68 Festival de Veneza, 2011), inspirado de forma livre na obra homónima de Johann Wolfgang von Goethe mas também no Fausto de Thomas Mann. Encontrei nos seis minutos e qualquer coisa do começo desse filme uma significativa resposta plástica, ética e crepuscular para algumas das interrogações suscitadas pela peça de Müller.

A obra de Sokurov segue por dentro e com grande sensibilidade estética os anseios físicos e metafísicos do Dr. Heinrich Faust por uma vida de liberdade e prazer. Situado o filme historicamente no séc. XIX - um século determinante por muitas e variadas razões para aquilo que hoje somos - e que Goethe celebrizou na sua tragédia em duas partes como mundividência universal, verificamos que as noções de liberdade e prazer estão permanentemente associadas ao puro exercício do poder em todas as formas possiveis. Essa constatação que pode responder pela complexidade da natureza da vida humana, não tem, ainda assim, de encontrar nela justificação suficiente para tudo o que de nefasto e irreparável uns aos outros fazemos.

\section{Referências bibliográficas}

BENJAMIN, Walter (1974), Abhandlungen: Charles Baudelaire. Ein Lyriker im Zeitalter des Hochkapitalismus, Gesammelte Schriften, vol. I-2,

Frankfurt am Main, Suhrkamp.

HELDER, Herberto (2013), Servidões, Lisboa, Assírio \& Alvim. 